\title{
Physical Fitness Is a Major Determinant of Femoral Neck and Lumbar Spine Bone Mineral Density
}

\author{
Nicholas A. Pocock, John A. Eisman,* Michael G. Yeates,‡ Phillip N. Sambrook, and Stefan Eberfł \\ *Garvan Institute of Medical Research, and $\ddagger$ Department of Nuclear Medicine, St. Vincent’s Hospital, Sydney, Australia
}

\begin{abstract}
The relationship between physical fitness and bone mass in the femoral neck, lumbar spine, and forearm was studied in 84 normal women. Femoral neck and lumbar spine bone mineral density and forearm bone mineral content were estimated by absorptiometry. Fitness was quantitated from predicted maximal oxygen uptake. Femoral neck and lumbar bone mineral density were significantly correlated with fitness as well as age and weight. In the $\mathbf{4 6}$ postmenopausal subjects, fitness was the only significant predictor of femoral neck bone mineral density, and both weight and fitness predicted the lumbar bone mineral density. These data represent the first demonstration of a correlation between physical fitness, and, by implication, habitual physical activity, and bone mass in the femoral neck; they also support the previous reported correlation between lumbar bone mass and physical activity. The data suggest that increased physical fitness may increase bone mass at the sites of clinically important fractures in osteoporosis.
\end{abstract}

\section{Introduction}

Osteoporosis is a major community health problem affecting up to half of the elderly female population in most Western countries (1). While the postmenopausal state is considered to be a major factor, decreased physical activity has also been reported to be significantly related to the development of osteoporosis (2-4).

Immobilization or weightlessness, as experienced by astronauts in space, is a well-known cause of significant and rapid loss of bone mineral (5-7). In athletes, conversely, bone density has been shown to be significantly higher than in age-matched controls (8-12). This effect appears to be most marked with sports that place a large stress on the skeleton (12). It has been postulated, after these studies in athletes, that physical activity is an important determinant of bone mass in the general population. However, evidence that variations in the level of activity, and hence physical fitness, observed in the "normal" population are significant determinants of bone mass has not been conclusively demonstrated.

It has been proposed that other life-style factors play a role in the maintenance of normal bone mass, e.g. weight, parity, and breast feeding (13-15). On the other hand, excess tobacco

This paper was presented in part at the 68th Annual Meeting or the American Endocrine.Society, and at the Eighth Annual Scientific Meeting of the American Society for Bone and Mineral Research, 1986.

Address correspondence to Dr. Eisman, Garvan Institute of Medical Research, St. Vincent's Hospital, Darlinghurst NSW 2010, Australia. Received for publication 5 March 1986.

J. Clin. Invest.

(c) The American Society for Clinical Investigation, Inc.

0021-9738/86/09/0618/04 \$1.00

Volume 78, September 1986, 618-621 and alcohol use have been implicated as possible aetiological factors for osteoporosis (14-17). If physical activity is an important determinant of bone mass, it is possible that the effects of various life-style factors on bone mass may be mediated through concomitant changes in physical activity. For example, detrimental effects of alcohol and tobacco may be due to associated changes in habitual physical activity. To clarify these important points we have studied the relationship between physical fitness, as an indicator of habitual activity, various life-style factors, and bone mass. Bone mineral density (BMD) ${ }^{1}$ was determined in the femoral neck and lumbar vertebrae and bone mineral content (BMC) in the distal forearm.

\section{Methods}

84 Caucasian women volunteers with no previous history of bone disease were studied. The age range was $20-75 \mathrm{yr}$, and 46 were postmenopausal. Informed consent was obtained from all subjects. Individuals with known heart disease were excluded, as were those on thyroxine or beta-blocking agents because of their possible effects on heart rate and consequently on the estimations of physical fitness. Three subjects were excluded from lumbar spine analysis on the basis of overlying calcification, scoliosis, or severe osteoarthritis. One subject did not undergo densitometry of the femoral neck, while nine did not have forearm measurements. Detailed medical histories were obtained that included parity, duration of breast feeding, age at menopause, and any previous illness. Subjects with a history of corticosteroid use or postmenopausal use of estrogens were excluded. Lifetime alcohol intake (kilograms ethanol) and tobacco use (pack years) were calculated from a life events-related alcohol and tobacco history (18).

BMD (grams per centimeter squared) was measured in the lumbar spine (lumbar 2-4) and right femoral neck using a Lunar DP3 dual photon absorptiometer (Lunar Radiation, Madison, WI). This instrument uses a Gadolinium 153 radiation source ( 44 and $100 \mathrm{keV}$ ). The radiation dose to the skin and ovaries is $<200$ and $100 \mu \mathrm{Gy}$, respectively (19). The direction of scanning was perpendicular to the long axis of the body. The region of interest in the femoral neck used to calculate BMD was in a transcervical position and was chosen so as to avoid the greater trochanter or adjacent bone of the pelvis. The coefficient of variation was $1.4 \%$ over 36 determinations (weekly) with cadaveric vertebrae and $2.6 \%$ on repeated determinations in five normal volunteers, which is consistent with published values (20). In 24 normal individuals there was a strong correlation between BMD in the right and left femoral neck $(r=0.97)$. The right femur was therefore measured in this study. Forearm BMC (units per centimeter) of the distal radius and ulna was measured using a Molsgaard Densitometer (Molsgaard Instruments, Copenhagen, Denmark). This instrument commences scanning at a site corresponding to $8 \mathrm{~mm}$ separation between the radius and the ulna. At this site the radius and ulna are $\sim 20$ and $12 \%$ trabecular bone, respectively (21). Five subsequent scans are performed, each $4 \mathrm{~mm}$ more proximal than the preceding scan. At the most proximal site both the radius and ulna are $\sim 5 \%$ trabecular bone (21). Forearm BMC is calculated as the mean of the six scans. The coefficient of variation was $2.5 \%$ on monthly measurements of a cadaveric forearm over a period of $8 \mathrm{mo}$.

1. Abbreviations used in this paper: BMC, bone mineral content; BMD, bone mineral density; $\mathrm{VO}_{2}$ max, maximum oxygen uptake. 
Physical fitness was quantitated by measurement of predicted maximal oxygen uptake $\left(\mathrm{VO}_{2}\right.$ max) according to the criteria of Astrand and Ryhming (22-24). Subjects were exercised with a submaximal stress on a bicycle ergometer at a constant speed. The workload was selected to maintain the pulse, which was monitored throughout at 120-170 beats/ $\mathrm{min}$. The plateau pulse rate, steady for at least $2 \mathrm{~min}$, was used in conjunction with the load and speed to estimate the $\mathrm{VO}_{2} \max$ (liters per minute) according to the nomogram of Astrand and Ryhming (23). The coefficient of variation of this technique from 15 repeat measurements in three normal subjects was $5 \%$.

Weight (kilograms) and height (centimeters) were measured in all volunteers. The menopausal status of the women was confirmed from measurements of follicle-stimulating hormone, luteinizing hormone, and estradiol. No subjects in the study had prior history of renal disease and all had normal renal function as assessed by creatinine clearances (available in 65 subjects) and/or a normal serum creatinine.

Statistical methods. Analysis was performed by simple linear regression and by stepwise multiple regression using the Minitab statistical package (Pennsylvania State University, University Park, PA). Student's $t$ test was used to test the significance of the partial regression coefficients.

\section{Results}

The mean age of the subjects studied was $49 \mathrm{yr} .30$ were or had been smokers, and in these, the mean tobacco use was 19 pack years. There were 64 subjects who drank alcohol, and for these the mean total life alcohol consumption was $62 \mathrm{~kg}$ ethanol. This represents less than one standard alcoholic drink per day from an age of 20 to the mean age of $49 \mathrm{yr}$.

Femoral neck. Femoral neck BMD was significantly positively correlated with $\mathrm{VO}_{2} \max (r=0.60, P<0.001)$, weight ( $r$ $=0.27, P<0.05)$, and height $(r=0.24, P<0.05)$. There was also a significant negative correlation with age $(r=-0.64, P$ $<0.001$ ). Further analysis by stepwise multiple regression found age, $\mathrm{VO}_{2}$ max, and weight to be independent significant predictors of femoral neck BMD $\left(r^{2}=0.5, n=83, P<0.001\right)$. The regression equation was: femoral neck $\mathrm{BMD}=0.81-0.0044$ (age) $+0.067\left(\mathrm{VO}_{2} \max \right)+0.0023$ (weight), and the partial regression coefficients were significant at the $0.001,0.005$, and 0.05 levels, respectively.

The significant correlation between femoral neck BMD and $\mathrm{VO}_{2}$ max in a multiple regression analysis indicates an independent relationship between these two parameters rather than an association due to their common relationship with one of the other variables, e.g. age. When these analyses were repeated in the postmenopausal women, $\mathrm{VO}_{2}$ max was the only significant predictor of femoral neck BMD $(r=0.46, n=45, P<0.01)$. The equation was: femoral neck $\mathrm{BMD}=0.61+0.11\left(\mathrm{VO}_{2} \max \right)$.

The importance of this relationship becomes evident by considering that a variation in $\mathrm{VO}_{2}$ max within the normal postmenopausal range of this study (i.e. mean $\pm 2 \mathrm{SD}$ ) corresponds to a $23 \%$ variation in the observed femoral neck BMD. Femoral neck BMD of the 38 premenopausal women was correlated with $\mathrm{VO}_{2} \max (r=0.32, P<0.05$, one tailed) and age $(r=-0.30$, $P<0.05$, one tailed) but not with weight. Fig. 1 shows the relationship between femoral neck $\mathrm{BMD}$ and $\mathrm{VO}_{2}$ max.

Lumbar spine. The results for the lumbar spine were similar to those for the femoral neck. Lumbar BMD was significantly positively correlated to $\mathrm{VO}_{2} \max (r=0.54, P<0.001)$, weight $(r=0.39, P<0.001)$, and height $(r=0.30, P<0.01)$. There was also a significant negative correlation with age $(r=-0.57$, $P<0.001$ ). Analysis by stepwise multiple regression found age, weight, and $\mathrm{VO}_{2}$ max to be independent significant predictors

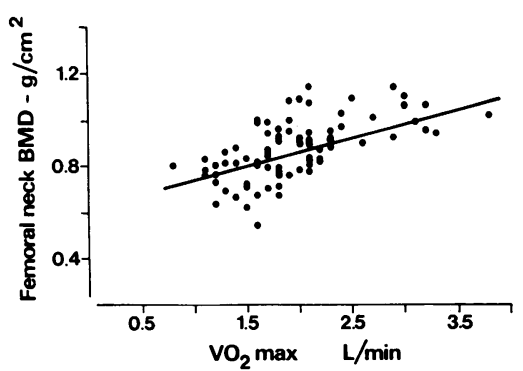

Figure 1. Plot of femoral neck BMD against physical fitness $\left(\mathrm{VO}_{2}\right.$ $\max )$ in 82 normal women. Equation for regression: femoral neck $\mathrm{BMD}=0.61+0.13\left(\mathrm{VO}_{2} \max \right)$.

of lumbar spine BMD $\left(r^{2}=0.45, n=81, P<0.001\right)$. The regression equation was: lumbar BMD $=0.91-0.0049$ (age) +0.0051 (weight) $+0.060\left(\mathrm{VO}_{2} \max \right)$, and the partial regression coefficients were significant at the $0.001,0.001$, and 0.05 levels, respectively.

In the postmenopausal women, lumbar BMD was significantly positively correlated with weight $(r=0.38, P<0.01)$ and $\mathrm{VO}_{2} \max (r=0.30, P<0.05)$. There was also a significant negative correlation with years postmenopause $(r=-0.29, P$ $<0.05$ ). However, further analysis by multiple regression found weight and $\mathrm{VO}_{2}$ max were the only independent significant predictors of lumbar BMD in this group $\left(r^{2}=0.20, n=44, P\right.$ $<0.001$ ). The equation was: lumbar $\mathrm{BMD}=0.44+0.0068$ (weight) $+0.10\left(\mathrm{VO}_{2} \mathrm{max}\right)$, and the partial regression coefficients were significant at the 0.01 and 0.05 levels, respectively.

Lumbar spine BMD of the premenopausal women was significantly correlated with weight $(r=0.45, P<0.01)$. There was no significant correlation with $\mathrm{VO}_{2}$ max or age. The relationship between lumbar BMD and $\mathrm{VO}_{2} \max$ is shown in Fig. 2 .

Forearm. In contrast to our findings for the axial skeletal sites, forearm BMC was significantly positively correlated with only $\mathrm{VO}_{2} \max (r=0.42, P<0.001)$. There was a significant negative correlation with age $(r=-0.58, P<0.001)$. However, further analysis by stepwise multiple regression found age to be the only significant independent predictor of forearm BMC. The regression equation was: forearm $\mathrm{BMC}=1.73-0.0082$ (age); $(r=-0.58, n=75, P<0.001)$. This suggests that the significant correlation observed between forearm BMC with $\mathrm{VO}_{2}$ max in simple regression may be due to the common relationship of these two parameters with age rather than an independent relationship (see below).

In the postmenopausal women, forearm BMC was significantly negatively correlated with age $(r=-0.58, P<0.001)$ and

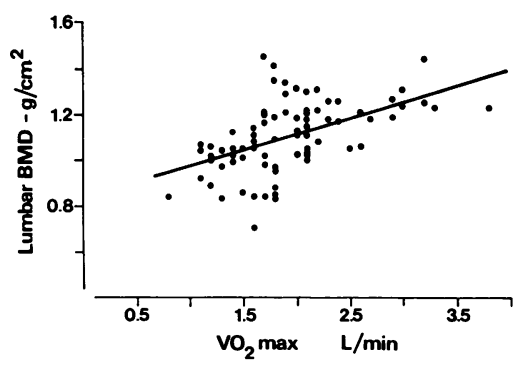

Figure 2. Plot of lumbar spine $\mathrm{BMD}$ against physical fitness $\left(\mathrm{VO}_{2}\right.$ $\max$ ) in 81 normal women. Equation for regression: lumbar BMD $=0.82+0.15\left(\mathrm{VO}_{2} \max \right)$. 
years postmenopause $(r=-0.33, P<0.05)$ but not with weight, height, or $\mathrm{VO}_{2}$ max. Forearm BMC of the premenopausal women was weakly correlated with age $(r=0.35, P<0.05)$. There was no significant correlation with $\mathrm{VO}_{2} \max$ or weight. Alcohol and tobacco usage, parity, and duration of breast feeding were not found to be significant factors in the determination of $\mathrm{VO}_{2}$ max or bone mass at any of the sites studied. $\mathrm{VO}_{2} \max$ was found to be significantly correlated with age $(r=-0.59, P$ $<0.001)$ and height $(r=0.30, P<0.01)$.

\section{Discussion}

These data clearly demonstrate that BMD of the femoral neck and lumbar spine in women are significantly related to variations in the level of physical fitness within the normal range. In particular; physical fitness is the only independent predictor of femoral neck BMD in postmenopausal women.

Bone mass and $\mathrm{VO}_{2}$ max are known to be significantly correlated with age, as shown here and previously observed $(20,22$, 25, 26). The associations of $\mathrm{VO}_{2} \max$ and bone mass might therefore be the result of the common relationship of both variables with age, rather than a direct correlation between $\mathrm{VO}_{2}$ max and bone. However, the finding of a significant correlation between $\mathrm{VO}_{2}$ max and axial bone mass, after accounting for the effect of age in a multiple regression, indicates that these two variables are independently related.

Reproducible quantitation of habitual physical activity is difficult. There is general acceptance that the maximum oxygen uptake, $\mathrm{VO}_{2}$ max, is a good index of aerobic working capacity or "fitness" (27). Because measurement of this parameter requires strenuous exercise, usually on a treadmill or bicycle ergometer, the direct measurement of $\mathrm{VO}_{2}$ max is not suited to middle-aged or elderly individuals. As an alternative, we have used values of $\mathrm{VO}_{2}$ max derived from submaximal exercise testing on a bicycle ergometer, which do not differ significantly from direct measurements of $\mathrm{VO}_{2}$ max on the ergometer $(24,28,29)$. While genetic factors may be important determinants, regular physical activity can result in an increase in $\mathrm{VO}_{2} \max (22,25$, 30). Furthermore, in a large study of occupational groups, individuals within physically active professions, or those who were physically active in their leisure time, were found to have higher values for $\mathrm{VO}_{2} \max (22)$. Similarly, Cotes et al. found $\mathrm{VO}_{2} \max$ to be significantly correlated to the customary physical activity determined by questionnaire (31). Our data, showing a relationship between $\mathrm{VO}_{2}$ max and $\mathrm{BMD}$, therefore supports the premise that habitual physical activity is an important determinant of bone mass in the femoral neck and lumbar spine in women.

Previous studies in athletes (10-12) and in animals $(32,33)$ suggest that there is primarily a local effect of exercise upon that part of the skeleton involved in the physical activity. However, because these studies represent such extremes of physical activity, there is difficulty in extrapolating to the general population. In this group, physical fitness and $\mathrm{VO}_{2}$ max are probably largely determined by activities involving the lower limbs, such as walking. The lack of a significant correlation in this study between forearm $\mathrm{BMC}$ and $\mathrm{VO}_{2}$ max would be consistent with the predominant physical activity, i.e. walking, which exerts a local effect upon the lower limbs and spine.

The apparent stronger correlation between fitness and femoral neck bone density, compared with lumbar spine bone den- sity, may also relate to the pattern of physical activity in the general population. Thus, while a change from a seated posture to walking will result in increased activity of the paraspinal muscles, there will be a relatively greater increase in weight loading and muscular activity of the lower limbs. This close relationship of lower limb load and muscular activity to exercise may be the explanation for the stronger correlation observed between femoral neck bone density and fitness.

There have been little data published previously as to whether the variation in physical activity or physical fitness, observed in the general population, is a significant factor in the determination of bone mass. Smith et al. concluded that factors other than physical activity were important in determining the rate of bone mineral loss in postmenopausal women (34). Conversely, Oyster et al. reported a positive correlation between activity, determined from a physical activity profile questionnaire, and bone mass assessed by measurements of metacarpal diameter (4). However, bone mass in both these studies was measured in the upper limbs, which may not reflect the effects of the predominant physical activity of daily living, i.e. walking, as well as the axial skeleton may. Further, there is data to suggest that the upper limb sites, which are largely cortical bone, do not accurately reflect the skeletal axial sites such as the lumbar spine and femoral neck, which have higher percentages of trabecular bone (35-37). Hence, those studies where only forearm measurements have been made may not reliably reflect any benefit, or lack thereof, of exercise on the more clinically important axial bone sites of the femoral neck and spine.

Krolner et al. reported a higher lumbar BMD, measured by dual photon absorptiometry, in a group of middle-aged women with a high work capacity, compared with a group with a low work capacity (38). This group did not find any difference in forearm BMC between the two groups. Black-Sandler et al. reported a positive correlation between bone mass in the tibia and radius and physical activity measured by means of an activity monitor worn for $3 \mathrm{~d}$ (2).

Two major prospective studies have demonstrated a positive effect of an exercise program on lumbar BMD and total body calcium $(39,40)$. We are unaware of any previous studies examining the relationship of bone mass to quantitative measurements of physical fitness. In particular we know of no previous studies that have demonstrated a relationship between physical fitness or habitual activity and femoral neck BMD in postmenopausal women. Femoral neck fractures in this group represent the most devastating effect of osteoporosis.

This study supports our recent finding that physical activity is an independent significant predictor of femoral neck BMD in patients with rheumatoid arthritis (Sambrook, P. N., J. A. Eisman, G. D. Champion, M. G. Yeates, N. A. Pocock, and S. Eberl, manuscript in preparation).

The lack of any significant correlation between alcohol and tobacco use and bone mineral measurements may be due to the relative moderate use of these agents by the subjects studied, and does not exclude deleterious effects on bone at higher levels of use.

In summary, this study has shown quantitatively for the first time the significant relationship between physical fitness, and, by implication, habitual physical activity, and bone mass of the femoral neck and lumbar spine. Importantly, physical fitness in this normal group accounted for $23 \%$ of the variation in femoral neck bone mineral density. These data support the premise that physical activity is a major determinant of femoral neck and 
lumbar spine bone mass. They suggest that increased physical activity may be a useful modality in prevention of fractures at these sites.

\section{Acknowledgments}

We thank Prof. Barry Wren, Royal Women's Hospital, Darlinghurst, Australia, for use of the forearm osteodensitometer.

These studies were supported by Sandoz Australia Pty. Ltd., Sydney, the Australian Dairy Corp., Melbourne, the New South Wales Dairy Corp., Sydney, and by the Garvan Research Foundation, Sydney, Australia.

\section{References}

1. Stevenson, J. C., and M. I. Whitehead. 1982. Postmenopausal osteoporosis. Br. Med. J. 285:585-588.

2. Black-Sandler, R., R. E. LaPorte, D. Sashin, L. H. Kuller, E. Sternglass, J. A. Cauley, and M. M. Link. 1982. Determinants of bone mass in menopause. Prev. Med. 11:269-280.

3. Chalmers, J., and K. C. Ho. 1970. Variations in senile osteoporosis. J. Bone Jt. Surg. 52B:667-675.

4. Oyster, N., M. Morton, and S. Linnell. 1984. Physical activity and osteoporosis in postmenopausal women. Med. Sci. Sports Exercise. 16 44-50.

5. Mazess, R. B., and G. D. Whedon. 1983. Immobilization and bone. Calcif. Tissue Int. 35:265-267.

6. Rambaut, P. C., and R. S. Johnston. 1979. Prolonged weightlessness and calcium loss in man. Acta Astronaut. 6:1113-1122.

7. Stewart, A. F., M. Adler, C. M. Byers, G. V. Segre, and A. E. Broadus. 1982. Calcium homeostasis in immobilization: an example of resorptive hypercalciuria. $N$. Engl. J. Med. 306:1136-1139.

8. Brewer, V., B. Meyer, M. S. Keele, S. J. Upton, and R. D. Hagan. 1983. Role of exercise in preventing involutional bone loss. Med. Sci. Sports Exercise. 15:445-449.

9. Dalen, N., and K. E. Olsson. 1974. Bone mineral content and physical activity. Acta Orthop. Scand. 45:170-174.

10. Huddlestone, A. L., D. Rockwell, D. N. Kulund, and R. B. Harrison. 1980. Bone mass in lifetime tennis athletes. J. Am. Med. Assoc. (JAMA). 244:1107-1109.

11. Jones, S. T., W. C. Hayes, C. C. Tichenor, and D. A. Nagl. 1977. Humeral hypertrophy in response to exercise. J. Bone Jt. Surg. 59A: 204-208.

12. Nilsson, B. E., and N. E. Westlin. 1971. Bone density in athletes. Clin. Orthop. Relat. Res. 77:179-182.

13. Nelson, B. E. 1969. Parity and osteoporosis. Surg. Gynecol. Obstet. 129:27-28.

14. Aloia, J. F., S. H. Cohn, A. Vaswani, J. K. Yeh, K. Yuen, and K. Ellis. 1985. Risk factors for postmenopausal osteoporosis. Am. J. Med. 78:95-100.

15. Daniell, H. W. 1976. Osteoporosis of the slender smoker. Vertebral compression fractures and loss of metacarpal cortex in relation to postmenopausal cigarette smoking and lack of obesity. Arch. Intern. Med. 136:298-304.

16. Saville, P. D. 1965. Changes in bone mass with age and alcoholism. J. Bone Jt. Surg. 37:492-499.

17. Vernejoul, M. C., J. Bielakoff, M. Herve, J. Gueris, M. Hatt, D. Madrowski, D. Kuntz, L. Mirovet, and A. Ryckewaert. 1983. Evidence for defective osteoblastic function. A role for alcohol and tobacco consumption in osteoporosis in middle aged men. Clin. Orthop. Relat. Res. 179:107-115.

18. Saunders, J. B., A. D. Wodak, A. Haines, P. R. Powell-Jackson, B. Portmann, M. Davis, and R. Williams. 1982. Accelerated development of alcoholic cirrhosis in patients with HLA B8. Lancet. i:1381-1384.

19. Wahner, H. W., W. L. Dunn, and B. L. Riggs. 1984. Assessment of bone mineral. J. Nucl. Med. 25:1241-1253.

20. Riggs, B. L., H. W. Wahner, E. Seeman, K. P. Offord, W. L.
Dunn, R. B. Mazess, K. A. Johnson, and L. J. Melton. 1982. Changes in bone mineral density of the femur and spine with aging. J. Clin. Invest. 70:716-723.

21. Schlenker, R. A. 1976. Percentages of cortical and trabecular bone mineral mass in the radius and ulna. Am. J. Radiol. 126:13091312.

22. Astrand, P. O., and K. Rodahl. 1970. Physical work capacity. In Textbook of Work Physiology. McGraw Hill, Inc., New York. 279-318.

23. Astrand, P. O., and I. Ryhming. 1954. A nomogram for calculation of aerobic capacity (physical fitness) from pulse rate during submaximal work. J. Appl. Physiol. 7:218-221.

24. Teraslinna, P., A. H. Ismail, and D. F. Macleod. 1966. Nomogram by Astrand and Ryhming as a predictor of maximum oxygen uptake. $J$. Appl. Physiol. 21:513-515.

25. Astrand, I. 1960. Aerobic work capacity in men and women with special reference to age. Acta Physiol. Scand. 49(Suppl. 169):11-26, 7987.

26. Riggs, B. L., H. W. Wahner, W. L. Dunn, R. B. Mazess, K. P Offord, and L. J. Melton. 1981. Differential changes in bone mineral density of the appendicular and axial skeleton with aging. J. Clin. Invest. 67:328-335.

27. Harrison, M. H., D. L. Bruce, G. A. Brown, and L. A. Cochrane. 1980. A comparison of some indirect methods for predicting maximal oxygen uptake. Aviat. Space Environ. Med. 51:1128-1133.

28. Glassford, R. G., G. H. Baycroft, A. W. Sedgwick, and R. B. Macnab. 1965. Comparison of maximal oxygen uptake values obtained by predicted and actual methods. J. Appl. Physiol. 20(3):509-513.

29. Harrison, M. H., G. A. Brown, and L. A. Cochrane. 1980. Maximal oxygen uptake: Its measurement application and limitations. Aviat. Space. Environ. Med. 51:1123-1127.

30. Kappagoda, C. T., R. J. Linden, and J. P. Newell. 1979. Effect of Canadian Air Force training programme on a submaximal exercise test. Quart. J. Exp. Physiol. 64:185-204.

31. Cotes, J. E., C. T. M. Davies, O. G. Edholm, M. J. R. Healy, and J. M. Tanner. 1969. Factors relating to the aerobic capacity of 46 healthy British males and females aged 18 to 28 years. Proc. R. Soc. Lond. B. 174:91-114.

32. Burr, D. B., R. B. Martin, and P. A. Martin. 1983. Lower extremity loads stimulate bone formation in the vertebral column: implications for osteoporosis. Spine. 8:681-686.

33. Lanyon, L. E., and C. T. Rubin. 1983. Regulation of bone mass in response to physical activity. In Osteoporosis, a Multidisciplinary Problem. A. St. J. Dixon, R. G. Russell, and T. C. Stamp, editors. Royal Society of Medicine. Academic Press, London. 55:51-61.

34. Smith, D. M., M. R. A. Khairi, J. Norton, and C. C. Johnston. 1976. Age and activity effects on rate of bone mineral loss. J. Clin. Invest. 58:716-721.

35. Mazess, R. B., W. W. Peppler, R. W. Chesney, T. A. Lange, U. Lindgren, and E. Smith. 1984. Does bone measurement on the radius indicate skeletal status. J. Nucl. Med. 25:281-288.

36. Sambrook, P. N., C. Bartlett, R. Evans, R. Hesp, D. Kaatz, and J. Reeve. 1985. Measurement of lumbar spine bone mineral: a comparison of dual photon absorptiometry and computed tomography. $\mathrm{Br}$. $\mathrm{J}$. Rad. 58:621-624.

37. Krolner, B., S. Pors Nielsen, B. Lund, B. J. Lund, O. H. Sorensen, and A. Uhrenholdt. 1980. Measurement of bone mineral content (BMC) of the lumbar spine. II. Correlation between forearm BMC and lumbar spine BMC. Scand. J. Clin. Lab. Invest. 40:665-670.

38. Krolner, B., E. Tondevold, B. Toft, B. Berthelsen, and S. Pors Nielsen. 1982. Bone mass of the axial and appendicular skeleton in women with colles fracture: its relation to physical activity. Clin. Physiol. 2:147-157.

39. Aloia, J. F., H. Stanton, J. A. Ostuni, R. Cane, and K. Ellis. 1978. Prevention of involutional bone loss by exercise. Ann. Intern. Med. 89:356-358.

40. Krolner, B., B. Toft, and S. Pors Nielson. 1983. Physical exercise as prophylaxis against involutional vertebral bone loss: a controlled trial. Clin. Sci. 64:541-546. 